\title{
A RESPONSABILIDADE PENAL EM TEMPOS DE PANDEMIA: DO DESCUMPRIMENTO DE MEDIDAS EMERGENCIAIS DE COMBATE À TRANSMISSÃO DA COVID-19 E SUAS CONSEQUÊNCIAS JURÍDICO-PENAIS
}

\author{
Airton Roberto Guelfi, Gisele Tafarelo Guelfi, Nathalia Horizonte Bacelar \\ Universidade do Oeste Paulista - UNOESTE, Presidente Prudente, SP. E-mail: del.guelfi@gmail.com
}

\begin{abstract}
RESUMO
Este artigo apresenta uma discussão teórica que parte do momento histórico-social presente diante da pandemia ocasionada pela COVID-19 frente ao aumento descontrolado de contaminações a nível mundial e consequentemente ao número crescente de óbitos. Tornou-se necessário ultrapassar o campo das ciências da saúde para uma análise jurídica, traçando um percurso o qual se instaura com as medidas governamentais através de atos administrativos editados pelo Executivo Federal e Estadual como meios de enfrentamento da pandemia. Com a edição desses atos administrativos há consequências criminais importantes que devem ser de fato observadas para que não se tornem letra morta no ordenamento jurídico. Todos os esforços do Estado enquanto gestor de uma política sanitária devem se apoiar nesse mesmo Estado enquanto gestor e executor de uma política criminal. Com base nesse fator o estudo aqui redigido, busca a realização de uma discussão sobre as repercussões que incidem sobre o campo do Direito Penal em decorrência do descumprimento das medidas impostas pelo Poder Público e a consequente responsabilização do agente infrator.

Palavras-chave: Pandemia. COVID-19.Medidas governamentais. Ordenamento jurídico. Consequências criminais. Direito penal. Responsabilização.
\end{abstract}

\section{CRIMINAL RESPONSIBILITY IN PANDEMIC TIMES: FROM BREACH OF EMERGENCY MEASURES TO COMBAT THE TRANSMISSION OF COVID-19 AND ITS LEGAL-CRIMINAL CONSEQUENCES.}

\begin{abstract}
This article introduce a theoretical discussion that starts from the historical-social moment present in the face of the pandemic caused by COVID-19 in face of the uncontrolled increase in contamination worldwide and, consequently, the increasing number of deaths. It became necessary to go beyond the field of health sciences for a legal analysis, tracing a path that is established with governmental measures through administrative acts edited by the Federal and State Executive as means to confront the pandemic. With the publication of these administrative acts, there are important criminal consequences that must in fact be observed so that they do not become a dead letter in the legal system. All efforts by the State as the manager of a health policy must be supported in that State as the manager and executor of a criminal policy. Based on this factor, the study written here seeks to conduct a discussion on the repercussions that affect the field of Criminal Law as a result of non-compliance with the measures imposed by the Government and the consequent liability of the offending agent.

Keywords: Pandemic.COVID-19.Government measures.Legal system.Criminal consequences.Criminal law.Accountability.
\end{abstract}




\section{INTRODUÇÃO}

O Direito Penal é um instrumento jurídico-normativo destinado a limitar o poder estatal, na medida em que seu "conjunto de normas jurídicas regulam o poder punitivo do Estado" (NORONHA, 1965, p. 04). Na mesma medida, a norma penal impõe aos cidadãos "a obrigação de agirem em conformidade com a mesma lei" (FERRI, 2009, p. 107).

Neste sentido, aquele cidadão que descumpre a norma penal, atingindo bens jurídicos de maior importância e atentando contra a paz jurídica, demonstra incapacidade de conviver em comunidade, sendo merecedor de uma pena (BRUNO, 1984, p.17-18). Em suma, aquele cidadão que concretiza a conduta descrita no fato típico receberá necessariamente uma pena, resultado direto de sua responsabilização penal.

A pandemia decorrente do novo coronavírus obrigou governantes do mundo todo a adotarem medidas emergenciais necessárias à contenção da propagação do vírus, assegurando a vida e a integridade física dos seres humanos. No Brasil, a lei 13.979/20 apresenta em seu artigo 3‥, (BRASIL, 2020a) o rol destas medidas, restringindo alguns direitos fundamentais do homem, como a liberdade de ir e vir, objetivandoconter a propagação do vírus, causador de danos à incolumidade pública, podendo até mesmo ocasionara morte.

Para garantir a eficácia destas medidas, 0 governo brasileiro editou diversas portarias ministeriais $^{1}$ operacionalizando a responsabilizaçãopenalatravés de leis ordinárias daqueles que as descumprem. Diante deste cenário, os operadores do Direito Penal viram-se frente a um desafio: tipificar a conduta daquele que desrespeita medidas emergenciais de combate a COVID-19sem que haja transmissãoe tipificar a conduta daquele que transmite o vírus a outrem,dolosa ou culposamente, sem necessariamente desrespeitar tais medidas emergenciais.

O presente artigo justifica-se pelo elevado grau de letalidade que a COVID-19 apresenta na sociedade, revelando-se a seguinte problemática: quais condutas potencialmente contaminadoras da COVID-19 poderão ser

\footnotetext{
${ }^{1}$ Portaria Interministerial no 9, de 27 de maio de 2020, do Ministério da Justiça e Segurança Pública; Portaria 356, de 11 de março de 2020, do Ministério da Saúde; e Portaria no 454, de 20 de março de 2020, do Ministério da Saúde.
}

tipificadas como infração penal perante o ordenamento jurídico brasileiro?

Entre as hipóteses penais possíveis de consideração estão o homicídio (CP, artigo 121), Lesão Corporal (CP, artigo 129), Perigo de Contágio de Moléstia Grave (CP, artigo 131), Epidemia (CP, artigo 267), Infração de Medida Sanitária Preventiva (CP, artigo 268) e Desobediência (CP, artigo 330).

Como objetivo geral, o presente artigo propõeapontar:quais os principais tipos penais serão aplicados diante da conduta daquele que desrespeita medidas emergências de combate a propagação da COVID-19?E quais os principais tipos penais serão considerados diante da conduta daquele que, mesmo não desrespeitando as medidas emergenciais, causam a contaminação de outrem pela COVID-19?

Como objetivos específicos, pretende-se explicar quais são as medidas emergenciais para o enfrentamento da COVID-19 no Brasil e identificar quais as principais infrações penais poderão ser aplicadas diante do descumprimento de tais medidase quais as principais infrações penais poderão ser aplicadas diante da efetiva transmissão do vírus a outrem.

Quanto a metodologia, a pesquisa será do bibliográfica-documental, através de uma abordagem qualitativa e com método dedutivo, aplicada sobre fontes primárias. $\mathrm{O}$ universo deste trabalho perfaz condutas comissivas e omissivas, praticadas no território brasileiro, responsáveis pela transmissão da COVID-19, durante o período da pandemia. A abordagem da pesquisa será qualitativa, aplicada sobre normas jurídicas préexistentes e posteriormente produzidas ao surgimento da COVID-19. A caracterização das infrações penais levará em consideração o Código Penal e leis penais especiais.Quanto ao método empregado, este será o dedutivo, identificando através das características das condutas investigadas, quais se qualificam como descumpridoras das medidas emergências de combate à transmissão da COVID-19.

\section{AS MEDIDAS EMERGENCIAIS DE ENFRENTAMENTO A COVID-19.}

A primeira notificação oficial recebida pela Organização Mundial de Saúde (OMS) sobre A COVID-19 ocorreu em 31 de Dezembro de 2019, quando casos de pneumonia na cidade de Wuhan, província de Hubei, na República Popular da China, haviam eclodido. Uma semana após, 
cientistas chineses confirmaram que tratava-se de uma nova espécie de coronavírus que estava atingindo a vida humana (OMS, 2020).

Mas foi em 30 de Janeiro de 2020, que a OMS declarou que o surto causado pela COVID19 constituía emergência de saúde pública de caráter internacional. $O$ estado de pandemia foi caracterizado pela OMS em 11 de Março de 2020 (OMS, 2020, não paginado).

No Brasil, as medidas de enfrentamento a emergência de saúde pública de caráter internacional estão previstasna lei 13.979, de 06 de Fevereiro de $2020^{2}$.Considerando o desrespeito destas medidas ou a transmissão da COVID-19, o exercício de subsunção da conduta concreta ao tipo penal abstratamente esculpido em norma penal exige sua compreensão jurídicodogmática.

Consoante referendado no artigo 1 . ., $\S 1$. ., da lei $13.979 / 20^{3}$, o objetivo das medidas emergenciais corresponde à proteção da coletividade, entendida como o conjunto de pessoas que formam a sociedade em que vivemos. A preservação e proteção da coletividade compreende um conjunto de ações e interesses relativos à vida, à saúde e a integridade física das pessoas, compreendida como a garantia da incolumidade pública social.

A duração da situação de emergência nacional de saúde pública, segundo o artigo 1‥, $\S 2$. . da lei $13.979 / 20^{4}$, deverá ser fixado através de ato do Ministro de Estado da Saúde. Curiosamente, quando da publicação da lei $13.979 / 20$, o estado de emergência em saúde pública de importância nacional já havia sido declarado através da Portaria n. 188, de em 03 de fevereiro de $2020^{5}$ (BRASIL, 2020d).

Entre as espécies de medidas de emergência que poderão ser adotadas durante a pandemia, segundo artigo 3‥, da lei 13.979/20, encontramos: o isolamento social; a quarentena; o estudo ou investigação epidemiológica; a exumação, necropsia, cremação e manejo de cadáver; a restrição excepcional e temporária, conforme recomendação técnica e

\footnotetext{
${ }^{2}$ Dispõe sobre as medidas para enfrentamento da emergência de saúde pública de importância internacional decorrente do coronavírus responsável pelo surto de 2019.

${ }^{3}$ Artigo 1‥, §1ㅇ., da lei 13.979/20 - As medidas estabelecidas nesta Lei objetivam a proteção da coletividade.

${ }^{4}$ Artigo 1ํ., §2ㅇ., da lei 13.979/20 - Ato do Ministro de Estado da Saúde disporá sobre a duração da situação de emergência de saúde pública de que trata esta Lei.

${ }^{5}$ Declara Emergência em Saúde Pública de importância Nacional (ESPIN) em decorrência da Infecção Humana pelo novo Coronavírus (2019-nCoV).
}

fundamentada da Agência Nacional de Vigilância Sanitária, por rodovias, portos ou aeroportos de entrada e saída do País e locomoção interestadual e intermunicipal; a requisição de bens e serviços de pessoas naturais e jurídicas, hipótese em que será garantido o pagamento posterior de indenização justa; a autorização excepcional e temporária para a importação de produtos sujeitos à vigilância sanitária sem registro na Anvisa, desde que registrados por autoridade sanitária estrangeira e previstos em ato do Ministério da Saúde; além de determinações de caráter compulsórios relacionados a exames médicos, testes laboratoriais, coleta de amostras clínicas, vacinação e outras medidas profiláticas e tratamentos médicos específicos. Todas essas medidas legais-administrativas visam a garantia da incolumidade pública.

Dentre as medidas citadas, as mais restritivas para a liberdade do cidadão são o isolamento social e a quarentena. São espécies de distanciamento social e resultam na mitigação das relações sociais numa dada comunidade, destinada a reduzir as taxas de transmissão de moléstias.

Conforme artigo 2‥, inciso I da lei $13.979 / 20$, isolamento deve ser entendido como a "separação de pessoas doentes ou contaminadas, ou de bagagens, meios de transporte, mercadorias ou encomendas postais afetadas, de outros, de maneira a evitar a contaminação ou a propagação do coronavírus."

Quando o isolamento for direcionado à pessoa, nos termos do artigo 3ㅇ., §1ํ.., da Portaria 356/2020 ${ }^{6}$ do Ministério da Saúde (BRASIL, 2020b), sua aplicação ocorrerá através de determinação médica ou por indicação de agente de vigilância epidemiológica, por prazo máximo de 14 dias, havendo possibilidade de extensão por igual período, conforme resultado laboratorial que comprove o risco de transmissão.

Já a quarentena, consoante artigo 3‥, inciso II da lei 13.979/20, deve ser entendida como a:

[...]restrição de atividades ou separação de pessoas suspeitas de

\footnotetext{
${ }^{6}$ Artigo 3o., §1‥, da Portaria 356/20 do Ministério da Saúde - A medida de isolamento somente poderá ser determinada por prescrição médica ou por recomendação do agente de vigilância epidemiológica, por um prazo máximo de 14 (quatorze) dias, podendo se estender por até igual período, conforme resultado laboratorial que comprove o risco de transmissão.
} 
contaminação das pessoas que não estejam doentes, ou de bagagens, contêineres, animais, meios de transporte ou mercadorias suspeitos de contaminação, de maneira a evitar a possível contaminação ou a propagação do coronavírus.

Nos termos do artigo 4ㅇ., §1ㅇ., da Portaria 356/2020 ${ }^{7}$ do Ministério da Saúde (BRASIL, 2020b), a quarentena é determinada por ato administrativo formal e motivado, devendo ser editada pelo Secretário de Saúde do Estado, do Distrito Federal, do Município ou Ministro de Estado da Saúde ou superiores em cada nível de gestão, e publicada no Diário Oficial com ampla divulgação pelos meios de comunicação.

A partir destas normas legais, torna-se possível concluir que o isolamento social é uma medida voltada a desagregar socialmente os indivíduos doentes, apresentando sintomas de determinada doença, como a COVID-19, de indivíduos sãos, buscando frustrar a propagação da doença. Por outro lado, a quarentena referese a contenção de atividades sociaispotencialmente contaminadoras entre pessoas que não apresentam sintomas, não havendo assim a certeza de contaminação. Entre os exemplos de quarentena que atualmente vigoram na sociedade brasileira estão o fechamento de escolas, as restrições comerciais, o cancelamento de eventos e a restrição de trabalhos de grupos em locais fechados, como escritórios, salões, e outros, eo uso de máscaras de proteção facial $^{8}$, entre outros.Tais medidas emergenciais poderão ser adotadas pelas autoridades competentes, nos termos do artigo 3‥, §7ㅇ.., da lei 13.979/20 ${ }^{9}$, nas esferas Federal, Estaduais e Municipais.

\footnotetext{
${ }^{7}$ Artigo 4ㅇ., §1ํ., da Portaria 356/20 do Ministério da Saúde - A medida de quarentena será determinada mediante ato administrativo formal e devidamente motivado e deverá ser editada por Secretário de Saúde do Estado, do Município, do Distrito Federal ou Ministro de Estado da Saúde ou superiores em cada nível de gestão, publicada no Diário Oficial e amplamente divulgada pelos meios de comunicação.

${ }^{8}$ Como exemplo de adoção de máscaras de proteção facial como medidas emergências em quarentena há o Decreto n. 64.959 de 04 de Maio de 2020, do Governador do Estado de São Paulo, que dispõe sobre o uso geral e obrigatório de máscaras de proteção facial no contexto da pandemia da COVID-19 e dá medidas correlatas.

${ }^{9}$ Artigo 3‥, §70., da lei 13.979/20 - As medidas previstas neste artigo poderão ser adotadas: I - pelo Ministério da Saúde, exceto a
}

Em recente conflito entre esferas do Poder Executivo, o Ministro Alexandre de Moraes, do STF(BRASIL, 2020c, não paginado), exarou liminar em Arguição de Descumprimento de Preceito Fundamental n. 672 - ADPF n. 672 de 08 de abril de 2020 - indicando que determinações legais de governadores e prefeitos destinadas a conter o avanço da COVID-19, como por exemplo, a quarentena, entre outros, devem ser tomadas como juridicamente legítimas, uma vez que a ordem jurídica constitucional assegura a estes entes federativos a competência para legislar sobre tema de saúde pública. Nas palavras do Ministro:

Em relação à saúde e assistência pública, inclusive no tocante à organização do abastecimento alimentar, a Constituição Federal consagra, nos termos dos incisos II e IX, do artigo 23, a existência de competência

administrativa comum entre União, Estados, Distrito Federal e Municípios.Igualmente, nos termos do artigo 24, XII, o texto constitucional prevê competência concorrente entre União e Estados/Distrito Federal para legislar sobre proteção e defesa da saúde; permitindo, ainda, aos Municípios, nos termos do artigo 30, inciso II, a possibilidade de suplementar a legislação federal e a estadual no que couber, desde que haja interesse local; devendo, ainda, ser considerada a descentralização políticoadministrativa do Sistema de Saúde (art. 198, CF, e art. 70 da Lei 8.080/1990), com a consequente descentralização da execução de serviços e

constante do inciso VIII do caput deste artigo; II - pelos gestores locais de saúde, desde que autorizados pelo Ministério da Saúde, nas hipóteses dos incisos I, II, V e VI do caput deste artigo; III - pelos gestores locais de saúde, nas hipóteses dos incisos III, IV e VII do caput deste artigo. IV - pela Anvisa, na hipótese do inciso VIII do caput deste artigo. 
distribuição dos encargos financeiros entre os entes federativos, inclusive no que diz respeito às atividades de vigilância sanitária e epidemiológica (art. 60, I, da Lei 8.080/1990).

Em suma, a lei 13.979/20 apresentou ao ordenamento jurídico brasileiro as medidas de caráter emergencial para o combate a pandemia da COVID-19, assegurando aos governos federal, estaduais e municipais a adoção de tais medidas em seus respectivos ambientes, possibilitando a responsabilização penal daqueles que as descumprem nos termos do Código Penal e Leis Penais Ordinárias Especiais.

\section{DO DESCUMPRIMENTO DAS MEDIDAS EMERGENCIAIS DE COMBATE À TRANSMISSÃO DA COVID-19 E SUAS CONSEQUÊNCIAS PENAIS.}

Diante da pandemia causada pela COVID19 , as nações foram obrigadas a adotar medidas sanitárias para a contenção do vírus e a consequente proteção do principal direito fundamental do ser humano: a vida.

A vida, bem jurídico de maior importância no ordenamento jurídico brasileiro, caracteriza-se como condição essencial para a existência e a prática de todos os demais direitos (MORAES, 2019, não paginado). Justifica-se tamanha relevância no fato da vida ser encarada como o máximo direito, anunciado pela Declaração Universal dos Direitos Humanos em seu art. III e protegido pela Constituição Federal em seu art. 5으, caput.

Tais ensinamentos expressam que a vida transcende sua concepção biológica, devendo ser usufruída com dignidade, nos termos do artigo 1‥, inciso III da CF. Sobre o tema, expõe José Afonso da Silva (2001, p.200)

Vida, no texto
constitucional $\begin{array}{r}\text { (artigo } \\ \text { 5o.,caput), não será } \\ \text { considerada apenas em }\end{array}$
seu sentido biológico de
incessante auto-atividade
funcional, peculiar à
matéria orgânica, mas na
sua acepção biográfica
mais compreensiva. Sua
riqueza significativa é de
difícil apreensão porque é
algo dinâmico, que se
transforma

incessantemente sem perder sua própria identidade. É mais um processo (processo vital), que se instaura com a concepção (ou germinação vegetal), transforma-se, progride, mantendo sua identidade, até que muda de qualidade, deixando, então, de ser vida para ser morte. Tudo que interfere em prejuízo deste fluir espontâneo e incessante contraria a vida."

\begin{abstract}
Para o exercício do direito à vida de forma digna, torna-se imprescindível a preservação da saúde, direito social constitucionalmente garantido pelo Estado, tornando-se legítimas as ações adotadas pelo poder público concernente às medidas de prevenção a propagação da contaminação da COVID-19 nos termos da lei 13.979/20. Diz a Constituição Federal (BRASIL, 1988, não paginado):
\end{abstract}

Art. 196. A saúde é direito de todos e dever do Estado, garantido mediante políticas sociais e econômicas que visem à redução do risco de doença e de outros agravos e ao acesso universal e igualitário às ações e serviços para sua promoção, proteção e recuperação.

Art. 197. São de relevância pública as ações e serviços de saúde, cabendo ao Poder Público dispor, nos termos da lei, sobre sua regulamentação,

fiscalização e controle, devendo sua execução ser feita diretamente ou através de terceiros e, também, por pessoa física ou jurídica de direito privado.

Tão importante quanto a saúde, tem-se o direito à integridade física como segunda vertente para o pleno exercício do direito à vida. No contexto vivido pela população mundial, a integridade física torna-se elemento garantidor 
da vida e da saúde, vez que "agredir o corpo humano é um modo de agredir a vida, pois está se realiza nesse. A integridade físico-corporal constitui, por isso, um bem vital e um direito fundamental." (SILVA, 2001, p. 202).

Pontuado o direito à vida, visto como aquele de viver de maneira digna (TAVARES, 2020, p. 437), com garantia à saúde e à integridade física, faz surgir para o Direito Penal a missão de intervir diante de condutas danosas e potencialmente lesivas em tempos de pandemia da COVID-19.

Durante o enfrentamento da pandemia causada pela COVID-19, foram vistas diversas medidas emergenciais voltadas à proteção da vida, saúde e integridade física, previstas na lei 13.979/20, assim nos tópicos subsequentes serão expostos os elementos tipificadores necessários para a criminalização das principais condutas daqueles que desrespeitamtais medidas e daqueles que transmitem $o$ vírus sem necessariamente desrespeitá-las. Envolvida neste cenário, a norma penal tem sua aplicação revelada através dos chamados "crimes de perigo" ${ }^{10}$, e "crimes de dano"11.

\subsection{Homicídio - artigo 121 do CP}

O crime de homicídio, classificado como um crime de dano, vem tipificado no artigo 121 do Código Penal com a seguinte redação: "Matar alguém: Pena - reclusão de 6 (seis) a 20 (vinte) anos". Na busca por uma concepção, Hungria (apud CAPEZ, 2019, pág. 60) nos ensina que o "homicídio é a morte de um ser humano provocada por outro ser humano. É a eliminação de uma pessoa praticada por outra. O homicídio é crime praticado por excelência."

A norma penal em comento objetiva proteger a vida extrauterina ${ }^{12}$. O corpo humano, receptáculo da vida, é o objeto material do homicídio, na medida que a conduta criminosa é voltada a atingi-lo.

\footnotetext{
${ }^{10}$ Crimes de perigo são aqueles cuja consumação ocorre com a possibilidade do dano ao bem juridicamente protegido sendo exemplos os crimes de perigo de contágio de moléstia grave $-\mathrm{CP}$, artigo 131 - e infração de medida sanitária preventiva $-\mathrm{CP}$, artigo 268. (ANDREUCCl, 2020).

${ }^{11}$ Crimes de dano são aqueles cuja consumação ocorre com a efetiva lesão ou diminuição ao bem jurídico protegido, sendo exemplos os crimes de lesão corporal - CP, artigo 129 - e homicídio - CP, artigo 121. (PACELLI; CALLEGARI. 2016).

12 "A vida começa com o início do parto, com o rompimento do saco amniótico; é suficiente a vida, sendo indiferente a capacidade de viver. Antes do início do parto, o crime será de aborto. Assim, a simples destruição da vida biológica do feto, no início do parto, já constitui o crime de homicídio" (BITTENCOURT, 2019).
}

O núcleo é o verbo "matar", não exigindo meio de execução específico, sendo considerado um crime de ação livre. Embora o verbo matar carregue um significado comissivo, é possível ainda que o homicídio seja praticado através de conduta omissiva, como na hipótese do agente que tendo o dever jurídico de evitar o resultado e podendo fazer, omite-se propositalmente para causar a morte de outrem (GONÇALVES, 2018, p. 76).

Quanto ao sujeito ativo, o crime de homicídio é classificado como um crime comum, posto que qualquer pessoa poderá figurar no polo ativo. Já o sujeito passivo, ou simplesmente vítima, será qualquer ser humano nascido com vida (BITENCOURT, 2019, p. 382).

Sobre o elemento subjetivo, o homicídio caracteriza-se tanto na modalidade dolosa, quanto culposa. A modalidade dolosa ocorrerá nas espécies direta e eventual. $\mathrm{O}$ dolo direto, também denominado animus necandi ou occidendi, caracteriza-se pela vontade do agente de provocar a morte de forma imediata e explícita. O dolo eventual, por sua vez, caracteriza-se na hipótese do agente prevendo a morte de outrem, assume o risco de provoca-la.

O homicídio culposo, por sua vez, ocorre quando o agente não desejando causar a morte da vítima e não assumindo o risco de provocá-la, acaba produzindo conduta revestida de imprudência, negligência ou imperícia, dando causa à morte.

A consumação do homicídio é verificada no instante da morte. No ordenamento jurídico brasileiro, a morte é verificada com a cessação da atividade encefálica, nos termos do artigo 3ㅇ.., da lei $9.434 / 97^{13}$.

O crime de homicídio, no contexto pandêmico da COVID-19, caracteriza-se diante da conduta daquele que transmite, dolosa ou culposamente, o vírus à outrem, ocasionando como resultado a efetiva morte do contaminado. Importante ressaltar que o tipo penal em comento não tem condicionada sua execução ao necessário desrespeito as medidas emergenciais presentes na lei $13.979 / 20$, exigindo apenas a efetiva contaminação da vítima.

\footnotetext{
${ }^{13} \mathrm{~A}$ retirada post mortem de tecidos, órgãos ou partes do corpo humano destinados a transplante ou tratamento deverá ser precedida de diagnóstico de morte encefálica, constatada e registrada por dois médicos não participantes das equipes de remoção e transplante, mediante a utilização de critérios clínicos e tecnológicos definidos por resolução do Conselho Federal de Medicina.
} 
É possível reconhecer a modalidade dolosa na conduta daquele que desejando matar um ascendente afortunado economicamente e debilitado em sua saúde, para herdar sua fortuna, Ihe oferta um lenço que acabou de ser utilizado por alguém contaminado pelo vírus, para limpar os olhos ou o nariz, causando sua contaminação e consequente morte. Importante lembrar que na modalidade dolosa, é admitida a tentativa.

Na mesma esteira, é possível reconhecer o homicídio, em sua modalidade culposa, na conduta daquele que desconsiderando as medidas de quarentena, abre as portas de seu comércio, permitindo que diversas pessoas se aglomerem e consequentemente haja contaminação entre os frequentadores, resultando na morte de qualquer um deles.

\subsection{Lesão Corporal - Artigo 129 do CP.}

O crime de lesão corporal, classificado como um crime de dano, vem esculpido no art. 129 do CP, com a seguinte redação: "Ofender a integridade corporal ou a saúde de outrem: Pena - detenção, de 3 (três) meses a 1 (um) ano".

$O$ bem juridicamente protegido é a integridade física e a saúde física ou mental. Para a ocorrência do crime, a conduta criminosa deverá atingir o corpo humano, objeto material representativo da integridade e da saúde, afetando-o interna ou externamente ( $\mathrm{NUCCl}$, 2019a, não paginado).

O núcleo do tipo é o verbo "ofender", compreendido como a conduta de prejudicar a integridade física ou a saúde de outrem, independentemente do meio de execução. No que se refere aos sujeitos do crime, a norma penal não exige qualidade específica para o autor e para a vítima. Há exceções legais quanto à vítima, como no caso da mulher grávida, que sofre aceleração de parto ou aborto (artigo 129, $\S 1 \stackrel{\circ}{\circ}, \mathrm{IV}$, e $\S 2 \circ, \mathrm{V}, \mathrm{CP})$.

Quanto ao seu elemento subjetivo, o crime admite tanto o dolo, quanto a culpa. A modalidade dolosa é externada pela vontade de lesionar, ao passo que a modalidade culposa se apresenta pela imprudência, negligência ou imperícia.A consumação ocorre com a efetiva lesão à integridade física ou a saúde de outrem, sendo classificado como um crime material. Quanto a tentativa, é admitida.

O crime de lesão corporal, no contexto pandêmico da COVID-19, caracteriza-se diante da conduta daquele que transmite, dolosa ou culposamente, a COVID-19 à outrem, provocando efetivo dano à integridade física ou a saúde de outrem. Importante ressaltar que o tipo penal em comento não tem condicionada sua ocorrência ao necessário desrespeito as medidas emergenciais presentes na lei 13.979/20, exigindo apenas a efetiva contaminação da vítima.

Como exemplo da modalidade dolosa, imaginea conduta do agente que de forma intencional, tosse próximo à outras pessoas, contaminando-as com a COVID-19, ou ainda na conduta daquele que de forma intencional, envia para outrem máscara de proteção facial contaminada pelo vírus, causandoa efetiva contaminação do destinatário. $\mathrm{Em}$ ambos os casos é preciso haver ofensa a integridade física ou saúde da pessoa contaminada.

O exemplo na modalidade culposa pode ser compreendido na conduta do agente de saúde que, negligentemente, deixa de realizar medidas de higiene necessárias a impedir a transmissão do vírus entre atendimentos de pacientes, vindo assim a contaminá-los.

\subsection{Perigo de Contágio de Moléstia Grave - artigo 131 do CP.}

O crime de "Perigo de contágio de moléstia grave", vem classificado pelo Código Penal como um crime de perigo. Sua previsão legal vem no artigo 131 do Código Penal, com a seguinte redação: "Praticar, com o fim de transmitir a outrem moléstia grave de que está contaminado, ato capaz de produzir o contágio: Pena - reclusão, de 1 (um) a 4 (quatro) anos, e multa."

Sua objetividade jurídica corresponde a incolumidade física e a saúde da pessoa. O tipo penal dispensa a efetiva lesão ao bem jurídico tutelado, por isso é denominado como crime de perigo concreto, caracterizando-se como infração penal individual, pois basta que a conduta seja direcionada à única pessoa (GONÇALVES, 2018, p. 172; CAPEZ, 2019, p. 259).

O objeto material é o corpo da pessoa destinatáriada conduta capaz de gerar contágio de moléstia grave.Apresenta-se como núcleo do tipo o verbo "praticar", significando realizar ou promover, podendo ser executado de forma livre, bastando prova de que a conduta é capaz de contaminar outrem.

Quanto ao sujeito ativo do crime, é classificado como crime próprio, considerando que somente o indivíduo que sabe ser portador 
de moléstia grave poderá praticá-lo. E como sujeito passivo qualquer pessoa (MASSON, 2017a, p. 146).

O elemento subjetivo será o dolo direto e específico, devendo haver finalidade de contaminar outrem, não bastando o desejo de praticar ato capaz de contaminar, descartando assim o dolo eventual e a culpa, pois não há previsão legal para esta última.

Sua consumação ocorrerá no momento em o agente produzir ato capaz de causar o contágio, mesmo que não ocorra a contaminação, pois está será considerada como mero exaurimento do crime (BITENCOURT, 2019, p. 448). A modalidade tentada é admitida quando a conduta criminosa for plurissubsistente.

A imputação do crime,no contexto pandêmico, se dá na conduta daquele que desejando transmitir a COVID-19, pratica ato capaz para tanto, sabendo estar contaminado. Importante ressaltar que o tipo penal em comento não tem condicionada sua consumação ao necessário desrespeito as medidas emergenciais presentes na lei $13.979 / 20$ ou a efetiva contaminação pela COVID-19.

Ocorrendo transmissão, a distinção para o crime de lesão corporal (CP, art. 129) dependerá da gravidade do resultado causado, ou seja, quando as lesões forem consideradas leves, mesmo a moléstia sendo grave, responderá o agente pelo crime de perigo de contágio de moléstia grave, que tem pena maior em comparação ao crime de lesão corporal $(\mathrm{CP}$, art. 129). Todavia, se as lesões produzidas forem consideradas graves ou gravíssimas responderá o agente pelo crime de lesão corporal qualificada CP, art. 129, §§ 1‥, e 2o.) (GONÇALVES, 2018, p. 173). Ocorrendo a morte, a tipificação será de homicídio doloso ou culposo, conforme o caso.

Importante destacar que se através do ato capaz de produzir o contágio de moléstia grave ocorrer a contaminação de um número excessivo de pessoas, estaremos diante de concurso formal entre os crimes de epidemia (CP, art. 267) e o crime em estudo (CAPEZ, 2019, p. 263).

Incorrerá no crime em testilha aquele que sabendo estar contaminado com o vírus,caminha entre pessoas determinadas, sem o uso de máscara, desejando produzir a transmissão da moléstia, sem efetivar a contaminação ou se efetivada, resultar em lesão leve.

\subsection{O crime de epidemia - artigo 267 do CP.}

O crime de Epidemia, éclassificado pela doutrina como um "crime de dano" e vem tipificado no artigo 267 do Código Penal com a seguinte redação: "Causar epidemia, mediante a propagação de germes patogênicos: Pena reclusão, de 10 (dez) a 15 (quinze) anos. A COVID19 é um germe patogênico.

O fato típico tem por objetividade jurídica a saúde pública. Seu objeto material é o germe patogênico, entendido como um "microorganismo capaz de produzir moléstia infectocontagiosa, nociva à saúde humana" (MASSON, 2017b, p. 315).

O núcleo do tipo é o verbo "causar", devendo ser entendido como produzir ou dar origem. A conduta criminosa é revelada pelo agente que causaa contaminação de um número indeterminado de pessoas, mediante a propagação de germes patogênicos. Sujeito ativo do crime poderá ser qualquer pessoa, estando ou não contaminado com o germe patogênico. Já o sujeito passivo é a coletividade (JESUS, 2020, não paginado).

O crime admite as modalidades dolosa e culposa. A dolosa é entendida como a vontade de propagar a doença a um número indeterminado de pessoas. A culposa é compreendida pela propagação do germe patogênico pela imprudência, negligência ou imperícia. Desta forma, a consumação ocorre no exato momento em que um número razoável de pessoas é efetivamente contaminado (NUCCl, 2019b, não paginado).

No contexto da pandemia da COVID-19, o crime estará caracterizado na conduta daquele que dá causa a contaminação de um grupo de pessoas presentes num determinado local. Importante ressaltar que o tipo penal em comento não tem condicionada sua execução ao necessário desrespeito as medidas emergenciais presentes na lei $13.979 / 20$, exigindo apenas a efetiva contaminação das vítimas.

Exemplificando a modalidade dolosa, incorrerá no crime em estudo o agente que se desloca até uma aldeia indígena, sabendo estar acometido pelo vírus, desejando transmitindo aos membros da tribo. A modalidade culposa poderá ser exemplificada na conduta do profissional de saúde que se desloca até uma comunidade ribeirinha a fim de realizar trabalho preventivo, sem contudo realizar a esterilização de seus equipamentos, contaminando toda a comunidade. 
3.5. O crime de infração de medida sanitária preventiva - artigo 268 do CP.

O crime proposto é classificado como um crime de perigo e vem tipificado no artigo 268 do Código Penal com a seguinte redação: "Infringir determinação do poder público, destinada a impedir introdução ou propagação de doença contagiosa: Pena - detenção, de um mês a um ano, e multa."

A objetividade jurídica é a incolumidade pública relacionada à saúde pública (CAMPOS et al, 2016). O objeto material são as medidas sanitárias determinadas pelo Poder Público para impedir a propagação de moléstia contagiosa ${ }^{14}$. Por esta razão, o crime exposto é classificado como uma norma penal em branco ${ }^{15}$, exigindo um acréscimo legal externo que complemente a descrição típica primária (MASSON, 2017b, p. 319).

O núcleo do tipo é o verbo "infringir", entendido como a conduta de desrespeitar ou violar a determinação sanitária da Administração Pública. Quanto ao sujeito ativo do crime, a norma penal não exige característica específica, logo sendo um crime comum, praticado por qualquer pessoa. Quanto ao sujeito passivo, será a coletividade.

Quanto ao elemento subjetivo, o crime admite apenas a modalidade dolosa, entendida como a vontade de desrespeitar medidas sanitárias destinadas a impedir a introdução ou propagação da doença contagiosa. Sobre o momento consumativo, estamos diante de um crime formal ${ }^{16}$, consumando-se no exato momento em que o agente descumpre determinação do poder público destinada a impedir a introdução ou propagação de doença contagiosa, pouco importando que tenha ocorrido ou não a efetiva transmissão (MASSON, 2017b, p. 320). Neste passo, caracteriza-se como um crime de perigo abstrato, havendo presunção absoluta de perigo para a saúde pública. Assim, preleciona BITENCOURT (2019, p.293)

Tratando-se de crime de perigo abstrato,

\footnotetext{
14 Essas determinações legais são expressadas através de leis, decretos, portarias, resoluções entre outras.

15 Importante destacar que a revogação da lei 13.979/20 não acarretará abolitio criminis, uma vez que as medidas para enfrentamento da emergência de saúde pública de importância internacional decorrente do coronavírus responsável pelo surto de 2019 possuí caráter excepcional consoante artigo 1ㅇ․, §3으.

${ }^{16} \mathrm{O}$ crime formal é conceituado por Estefam e Gonçalves (2016) com a seguinte descrição: Os crimes formais são aqueles cujo tipo penal descreve uma conduta e um resultado, contentando-se com a conduta, dirigida ao resultado, para a consumação.
}

desnecessário para sua configuração a efetiva introdução ou propagação de doença contagiosa. Contudo, será necessário demonstrar a idoneidade do comportamento infrator para produzir um potencial resultado ofensivo à preservação do bem jurídico saúde pública, visto sob a perspectiva genérica, caso contrário, a conduta será atípica, pela sua insignificância.

Na conjuntura da pandemia da COVID-19, a responsabilização penalpelo crime em estudo restará configurada diante da violação das medidas emergenciais do art. 30 da Lei 13.979/20.0 tipo penal em comento tem condicionada sua consumação ao desrespeito as medidas emergenciais presentes na lei $13.979 / 20$, sem contudo exigir a efetiva contaminação de outrem pelo vírus.

A título de exemplificação, imagine a conduta daquele agente que devendo permanecer em isolamento por estar contaminado, desrespeita a determinação, circulando por lugares públicos. Ou a conduta do diretor de uma escola particular que, desrespeitando medida de quarentena, abre as portas da escola, retomando as aulas. Em ambos os casos, não há exigência de efetiva transmissão para a consumação.

\subsection{Desobediência - artigo 330 do CP.}

O crime de desobediênciaé classificado como um crime de dano e vem tipificado no art. 330 do Código Penal com a seguinte redação: "Desobedecer a ordem legal de funcionário público: Pena - detenção, de quinze dias a seis meses, e multa."

O bem jurídico protegido é a Administração Pública, representada em seu prestigio perante a sociedade, por essa razão, dizse que o objeto material do crime é a ordem legal exarada pelo funcionário público.

A conduta criminosa é externada pelo verbo "desobedecer", entendido como desatender ou recusar o cumprimento da ordem 
legal. O sujeito ativo do crimeserá qualquer pessoa, uma vez que todos estão sob o império da lei, e o sujeito passivo imediato será o Estado e o sujeito passivo mediato será o funcionário público que tem sua ordem desrespeitada.

O elemento subjetivo deste crime é o dolo, entendido como a vontade livre e consciente de desobedecer aordem legalmente anunciada por funcionário público (JESUS, 2020, não paginado). A consumação do crime se dará no exato momento em que o agente desrespeita de forma comissiva ou omissiva a ordem legal.

No contexto da pandemia da COVID-19, o tipo penal em comento não tem condicionada sua consumação ao necessário desrespeito as medidas emergenciais presentes na lei 13.979/20, assim como não exigi também a efetiva contaminação de outrem pelo vírus.

Importante realçar que o crime de desobediência não deve ser confundido com o crime de "Infração de Medida Sanitário Preventiva", do artigo 268 do Código Penal. No crime de desobediência, o autor desatende uma ordem legal que the é direcionada por funcionário público, no exercício da função, ao passo que no crime de infração de medida sanitária preventiva, há 0 desrespeito a determinação contida abstratamente em ato normativo do poder público, destinada a impedir a propagação de determinada doença.

Como exemplo do crime em estudo imagina-se a ordem legal exarada por policial determinando que certo idoso retorne para seu lar diante de determinação de restrição de circulação fixada em decreto.

\section{CONSIDERAÇÕES FINAIS}

O presente trabalho eclodiu com o propósito de analisar a responsabilidade penal no contexto da pandemia ocasionada a partir da propagação da COVID-19. Portanto conclui-se que:

1. Ocorrendo conduta dolosa capaz de desrespeitar medidas emergências previstas na lei $13.979 / 2020$, sem efetiva contaminação de outrem, haverá a responsabilização pelo crime de infração de medida sanitária preventiva (CP, art. 268).

2. Ocorrendo conduta dolosa ou culposa que cause a efetiva transmissão, independentemente desteresultado ter ocorrido por desrespeito as medidas emergências, os crimes possíveis serão o homicídio (CP, art. 121), a lesão corporalqualificada (CP, art. 129, §§ 1‥, e 2‥) ou a epidemia (CP, art. 267).

3. Ocorrendo conduta dolosa, por quem está contaminado, capaz de transmitir aCOVID-19 ou mesmo transmitindo a COVID-19, mas resultando lesão leve, independentemente do desrespeito às medidas emergenciais da lei 13.979/20, o crime tipificado será de perigo de contágio de moléstia grave ( $C P$, art. 131).

4. Ocorrendo conduta dolosa,capaz de desobedecer aordem legalmente exarada por funcionário público destinada a impedir a propagação da COVID-19, não sendo esta ordem legal fundamentada nas medidas emergenciais da lei $13.979 / 20$, o crime tipificado será de desobediência (CP, art. 330).

\section{REFERÊNCIAS}

ANDREUCCl. Ricardo Antônio. Manual de Direito

Penal. 14. ed. São Paulo: Saraiva Educação. 2020.

ANVISA - Agência Nacional de Vigilância Sanitária.Nota técnica GVIMS/GGTES/ANVISA № 04/2020: orientações para serviços de saúde: medidas de prevenção e controle que devem ser adotadas durante a assistência aos casos suspeitos ou confirmados de infecção pelo novo coronavírus (sars-cov-2). São Paulo, 2020.

Disponível em:

https://portaldeboaspraticas.iff.fiocruz.br/atenca o-recem-nascido/covid-19-orientacoes-da-anvisapara-servicos-de-saude/.Acesso em: 02 jun. 2020.

BITENCOURT, Cezar Roberto. Tratado de direito penal: crimes contra a pessoa. 19. ed. São Paulo: Saraiva Educação, 2019.Parte 2.

BRASIL. Constituição (1988). Constituição da República Federativa do Brasil. Brasília: Senado Federal, 1988. Disponível em: http://www.planalto.gov.br/ccivil 03/constituica o/constituicaocompilado.htm. Acesso em: 24 maio 2020.

BRASIL. Congresso Nacional. Lei 13.979, de 06 de Fevereiro de 2020. Dispõe sobre as medidas para enfrentamento da emergência de saúde pública de importância internacional decorrente do coronavírus responsável pelo surto de 2019. Diário Oficial da União, Brasília 07 fev. 2020a. Disponível 
em:http://www.planalto.gov.br/ccivil 03/ ato20 19-022/2020/lei/L13979compilado.htm. Acesso em: 21 maio 2020.

BRASIL. Ministério da Saúde. Portaria 188, de 03 de Fevereiro de 2020. Declara Emergência em Saúde Pública de importância Nacional (ESPIN) em decorrência da Infecção Humana pelo novo Coronavírus (2019-nCoV). Diário Oficial da União, Brasília, DF, 04 Fev. 2020d. Disponível em:http://www.planalto.gov.br/ccivil 03/portari a/prt188-20-ms.htm. Acesso em: 23 maio2020.

BRASIL. Ministério da Saúde. Portaria 356, de 11 de Março de 2020. Dispõe sobre a regulamentação e operacionalização do disposto na Lei $n$ o 13.979, de 6 de fevereiro de 2020, que estabelece as medidas para enfrentamento da emergência de saúde pública de importância internacional decorrente do coronavírus (COVID19). Diário Oficial da União, Brasília, DF, 12 Mar. 2020b. Disponível em:

http://www.in.gov.br/en/web/dou/-/portaria-n356-de-11-de-marco-de-2020-247538346.

Acesso em: 28 maio 2020.

BRASIL. Supremo Tribunal Federal . Arguição de descumprimento de preceito fundamental 672 Distrito Federal. Reqte(s): Conselho Federal da Ordem dos Advogados do Brasil - CFOAB. Intdo.(a/s) :Presidente da República; Ministro De Estado Da Economia. Relator: Min. Alexandre De Moraes. Brasília, 08 de Abril de 2020c. Disponível em:

http://www.stf.jus.br/portal/autenticacao/autent icarDocumento.asp sob o código 7E45-E467391A-6532 e senha 2E6A-6071-45D3-3BF2. Acesso em: 25 maio 2020.

BITTENCOURT, Cézar Roberto. Código Penal Comentado. 10. ed.São Paulo: Editora Saraiva, 2019.

BRUNO, Aníbal. Direito Penal: pena e medida de segurança. 4. ed.Rio de Janeiro: Editora Forense. 1984.Tomo 3.

CAMPOS, Pedro Franco de. THEODORO, Luís Marcelo Mileo. BECHARA, Fabio Ramazzini. ESTEFAM, André. Direito Penal Aplicado: parte geral e parte especial do Código Penal. 6. ed.São Paulo. Saraiva. 2016.
CAPEZ, Fernando. Curso de Direito Penal: parte especial (arts. 121 a 212). 19 .ed. São Paulo: Saraiva Educação, 2019.

FERRI, Enrico. Princípios de Direito Criminal:o criminoso e o crime. 3. ed.Campinas: Russell Editores, 2009.

GONÇALVES, Victor Eduardo Rios. Curso de Direito Penal: parte especial (arts. 121 a 183).2.ed. São Paulo: Saraiva, 2018.v. 2.

JESUS. Damásio Evangelista de. Direito Penal: crimes contra a pessoa a crimes contra o patrimônio - arts 121 a 183do CP.36. ed.São Paulo: Saraiva Educação, 2020.v. 2. parte especial.

MASSON, Cleber. Direito Penal. São Paulo: Editora Método, 2017a.v. 2 parte especial.

MASSON, Cleber. Direito Penal: arts 213 a 359H.7 ed. São Paulo: Editora Método,2017b.v. 3. parte especial.

MORAES, Alexandre de. Direito Constitucional. 35. ed. São Paulo. Editora Atlas, 2019.

NORONHA. Edgard Magalhães. Direito Penal. 3. ed. São Paulo: Editora Saraiva, 1965.v. 1.

NUCCl, Guilherme de Souza. Direito Penal: partes geral e especial.6. ed. São Paulo: Editora Método, 2019a.

NUCCl, Guilherme de Souza. Curso de direito parte especial: arts. 213 a 361 do código penal. 3.ed. Rio de Janeiro: Editora Forense. 2019b.

OMS. Organização Mundial da Saúde. Folha Informativa sobre COVID-19. Brasília: OMS, 2020. Disponível em:https://www.paho.org/bra/index.php?option =com content\&view=article\&id=6101: covid19\&/t emid=875. Acesso em: 23 maio 2020.

ORGANIZAÇÃO DAS NAÇÕES UNIDAS. Declaração Universal dos Direitos Humanos, 1948.Disponível em: https://brasil.un.org/pt-br/91601declaracao-universal-dos-direitos-humanos. Acesso em: 24 maio 2020. 
PACELLI, Eugênio; CALLEGARI, André. Manual de Direito Penal: Parte Geral. 2.ed. São Paulo:

Editora Atlas, 2016.

SILVA, José Afonso. Curso de Direito

Constitucional Positivo. 19.ed. São Paulo. Editora Malheiros. 2001.

TAVARES, André Ramos. Curso de Direito

Constitucional. 18. ed. São Paulo: SaraivaJur, 2020. 